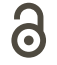

OPEN ACCESS

EDITORES

- Miguel Oliveira, Jr. (UFAL)

- René Almeida (UFS)

AVALIADORES

- Ana Elisa Ribeiro (CEFET-MG)

- Adolfo Tanzi Neto (UFRJ)

DATAS

- Recebido: 07/10/2020

- Aceito: 17/11/2020

- Publicado: 23/04/2021

COMO CITAR

PAIVA, Vera Lúcia Menezes de Oliveira e (2021). Tecnologia digital em época de pandemia. Cadernos de Linguística, v. 2, n. 1, p. 01-12.
ENSAIO TEÓRICO

\section{TECNOLOGIA DIGITAL EM ÉPOCA DE PANDEMIA}

\author{
Vera Lúcia Menezes de Oliveira e PAIVA ID $\boldsymbol{D}$ \\ Universidade Federal de Minas Gerais (UFMG)
}

\section{RESUMO}

Este texto discute tecnologias de comunicação e informação tendo como suporte a teoria da inovação e alguns conceitos da complexidade e do caos para apontar como a inovação tecnológica vem mudando o mundo. O ensaio mostra que os avanços nas comunicações são seguidos por algumas tentativas de censura para, em seguida, refletir sobre a pandemia do COVID-19 e a difusão da inovação. Faz-se uma digressão para contar a história da Internet no Brasil e, em seguida, avalia que estávamos a caminho da fase de difusão da normalização quando a pandemia obrigou professores e alunos a migrar para o mundo virtual.

\section{ABSTRACT}

This text discusses communication and information technology having as support the theory of innovation and some concepts of complexity and chaos to point out how technological innovation has been changing the world. It shows that the advancements in communications are followed by some attempts of censorship and then reflects about COVID-19 pandemic and the diffusion of innovation. A digression is made to tell the history of the Internet in Brazil followed by the claim that we were on the way to the diffusion stage of normalization when the pandemic forced teachers and students to migrate to the virtual world.

\section{PALAVRAS-CHAVE}

Tecnologias de Comunicação e Informação; Inovação; Pandemia;

Mundo Virtual .

\section{KEYWORDS}

Communication and Information Technologies; Innovation; Pandemic; Virtual World. 


\section{INTRODUÇÃO}

Começo este texto agradecendo à Associação Brasileira de Linguística (ABRALIN) pela oportunidade que me deu de fazer a primeira "live" de minha vida no evento ABRALIN ao Vivo, no dia 8 de maio de 2020, disponível no YouTube (https://aovivo.abralin.org/lives/veramenezes/). A seguir, com algumas edições, apresento o texto que foi objeto de minha conversa naquele dia.

Naquela ocasião, agradeci a Miguel Oliveira Jr., presidente da ABRALIN, e reitero meu apreço por ele e minha admiração pela excelente gestão frente à ABRALIN, pelo seu papel agregador e sua visão ampliada do que são os estudos da linguagem.

A ABRALIN foi pioneira ao organizar um evento no YouTube e conseguiu reunir pesquisadores de várias partes do mundo. O acervo de vídeos gerados é um acervo valioso para a humanidade tal a diversidade dos temas discutidos e dos pesquisadores convidados.

Neste texto vou, DESCARADAMENTE, me valer do autoplágio, de coisas que já escrevi, ora copiando, ora ampliando e ora recontextualizando para o tempo presente, o tempo da pandemia. Farei isso sem citar referências para tornar o texto mais fluido.

Ao rever o que escrevi para me preparar para a apresentação no evento ABRALIN ao Vivo, reli autores que citei e fiz novas conexões dentro do contexto da pandemia. Foi assim com Maquiavel. Uma simples epígrafe que usei em um capítulo de um livro em homenagem a Vilson Leffa (PAIVA, 2012) me fez reler o capítulo IV de O Príncipe de Maquiavel (1973) e vi quão atual é aquele texto. Falarei disso daqui a pouco

Ao fazer minhas reflexões sobre tecnologia digital em época de pandemia, vou apoiar minhas reflexões na teoria da inovação e em conceitos da complexidade e do caos.

\section{INOVAÇÃO}

Rogers (1995, xvii), na introdução de um livro sobre difusão da inovação, define inovação como "ideia, prática ou objeto que é percebido como algo novo por um indivíduo ou por outra unidade de adoção"1. Inovação não é sinônimo de invenção de uma nova tecnologia. Pode ser apenas uma nova forma de agir. Cumprimentar com os cotovelos é um bom exemplo de inovação que emergiu na pandemia em função da nossa necessidade de não abraçar as pessoas e nem apertar suas mãos. Mas nem sempre as pessoas tem uma percepção adequada da inovação e de sua função e houve quem passou a usar uma variação preocupante: bater as mãos fechadas. Esse gesto não impede a contaminação. 
Mas vamos falar de inovação também como invenção. Vamos falar de inovação na linguagem. Uma hipótese que eu considero fascinante é da a composição formulaica oral. Essa hipótese, defendida por Milman Parry, nos anos 30, é abonada por Gleick, no livro The Information: a history, a theory, a flood, traduzido no Brasil como A informação: Uma história, uma teoria, uma enxurrada. Eu teria traduzido flood como inundação.

Parry, em sua hipótese da composição formulaica oral, defende que a llíada e a Odisséia foram compostas e cantadas antes da escrita. Segundo essa hipótese,

A métrica, a redundância formulaica, na verdade a própria poesia das grandes obras serviam primeiramente e acima de tudo para ajudar a memória. Seu poder encantatório fez do verso uma capsula do tempo, capaz de transmitir uma cultura virtual através das gerações (GLEICK, 2011, posição 6116)

Para Parry, os poetas tinham um estoque de fórmulas que, em condições métricas semelhantes, eram usadas para compor os versos.

Se os versos serviam de cápsula do tempo, imagina o poder do alfabeto. Segundo Gleick (posição 605), "o alfabeto se espalhou por contágio A nova tecnologia era tanto o vírus como seu vetor de transmissão". Acho que Gleick, em 2011, não sonharia com o poder dessa metáfora do vírus: o alfabeto como vírus e ao mesmo tempo como seu vetor.

Gleick (2011, posição 611) diz que a transcrição da llíada e da Odisseia teve um grande impacto em nossa cultura e, citando Havelock (1986), afirma que a escrita foi "uma intrusão irreversível na cultura. Ela criou a base para a destruição do modo de vida oral e dos modos orais de pensamento" (GLEICK, 2011, posição 610-618). Surgiram novos gêneros, novas palavras e novas ideias. Acho que ele não imaginava que a oralidade voltaria com força no WhatsApp, no Tik Tok e no YouTube.

Gleick (2011) lembra que Platão alertou que a escrita iria alijar a multidão (os preletrados), pois ela seria incapaz de aceitar a ideia da beleza no lugar das coisas belas. Para ele a multidão não seria capaz de filosofar.

Vale a pena ler o livro de Gleick - A Informação. Ele discute a questão da informação desde os tambores da África (tambor+línguas tonais), passando pela criação dos alfabetos, do telégrafo, do telefone até chegar aos computadores.

Tanto o livro como o computador são artefatos que trazem nova energia ou informação ao sistema social e suas inserções nas práticas de linguagem foram responsáveis pela transformação de padrões de comportamentos linguísticos, tanto nos comportamentos micros, na interação entre as pessoas, quanto nos comportamentos de comunicação de massa. 


\section{A DIFUSÃO DAS INOVAÇÕES NA ESCRITA: DO LIVRO AO CELULAR}

A escrita mudou o comportamento humano, pois a memória deixou de ser a única forma de preservação da informação. As bibliotecas eram a extensão de nossa memória, hoje é a web, os pen-drives (já foi o disquete, o CD) e o armazenamento nas nuvens.

Como dizia Chartier (1994, p. 23) "a cultura escrita é inseparável dos gestos que a reprimem" e, talvez, hoje pudesse dizer que a tecnologia da informação é inseparável dos gestos que a reprimem.

Inúmeros são os exemplos dos gestos de repressão ao livro, ao computador e às inovações em geral ao longo da história da humanidade, pois essas inovações podem desestabilizar o poder. É por isso que os governos autoritários tanto temem as tecnologias de informação. Elas são armas de resistência e por isso precisam ser controladas.

A igreja católica, por exemplo, sempre foi uma fonte incansável de censura. Logo após a criação da imprensa, a igreja criou sua lista de livros proibidos, o famoso index que foi reformulado em 1948 e abolido no século passado pelo papa João Paulo VI.

Durante a ditadura no Brasil, muitas leituras foram proibidas nas escolas e a posse de alguns livros podia levar seus donos à prisão. Um exemplo era o Diário do Chê Guevara que podia ser comprado nas livrarias, mas sua posse era sinônimo de resistência à ditadura e seu dono corria o risco de ser preso.

Mesmo após a extinção do index, a igreja católica continuou tentando impedir seus fieis de lerem determinados livros e censurou até mesmo seus teólogos como foi o caso de Leonardo Boff no Brasil e do espanhol Marciano Vidal. Vidal foi repreendido pelo Vaticano, em fevereiro de 2012, acusado, como li nos jornais da época, de tentar justificar "a masturbação, a contracepção, a inseminação artificial e a liberação judicial do aborto”. Ele teve censurada, por denúncia do clero local, a edição argentina de seu livro (VIDAL, 2012) que faz um histórico da abordagem da homossexualidade na Igreja Católica. Isso me lembra a fala tresloucada do maestro Montovani, então presidente da FUNARTE, no Brasil: "O rock ativa a droga que ativa o sexo que ativa a indústria do aborto. A indústria do aborto por sua vez alimenta uma coisa muito mais pesada que é o satanismo".

Atualmente, a bola da vez do governo do ódio é Paulo Freire. Ele é demonizado por pessoas que, muito provavelmente, não leram suas obras. Outra bola da vez é a imprensa. Jornalistas e cinegrafistas sofrem ameaças e agressões físicas.

Mas eles não são os únicos a documentar o que acontece no mundo. De posse de um celular, todos nós podemos registrar os acontecimentos. Uma inovação tecnológica faz emergir novos comportamentos na linguagem. Essa ideia de emergência está presente na definição de inovação de Fonseca (2002, p.3). Ele define inovação como "continuidade emergente e transformação de padrões da interação humana, compreendida como 
processos responsivos complexos e ininterruptos de relacionamento em situações locais cotidianas". O celular e a Internet mudaram nossos hábitos linguísticos.

A emergência de novos padrões sempre gera estranhamentos. Maquiavel (1973), no século XIV, já alertava sobre as dificuldades e os perigos da inovação no capítulo $\mathrm{VI}$, com o título "Dos principados novos que se conquistam com as armas próprias e virtuosamente". Em um trecho desse capítulo, Maquiavel chama a atenção sobre a dificuldade que um chefe, um líder, enfrenta para introduzir novas leis,

pois terá como inimigos todos os que se beneficiavam das antigas leis e como defensores fracos todos os que se beneficiarão com as novas leis. Essa fraqueza nasce, em parte, por medo dos adversários, que tem a lei ao lado deles, em parte, da incredulidade dos homens, que, na verdade, não creem nas coisas novas até verem nascer uma firme experiência (MAQUIAVEL, 1973, p. 30).

A inovação não apenas ameaça aqueles que lucram com os comportamentos já arraigados na sociedade. Tira da zona de conforto os que se veem forçados a mudar seu comportamento. Como enfatiza Rogers (1995, xvii), o sentido da inovação é produzido gradualmente através de um processo de construção social. Isso nos remete ao conceito de difusão da inovação.

Rogers (1995, p. 5) define difusão como "o processo pelo qual a inovação é comunicada entre membros de um sistema social por meio de certos canais ao longo do tempo. É um tipo especial de comunicação, pois a mensagem se preocupa com novas ideias".

A inovação, afirma Rogers (2005, p.10), "vem de fora do sistema, geralmente via um inovador ou primeiros adeptos". Esses primeiros usuários funcionam como modelos ou formadores de opinião e aumentam a perturbação no sistema em virtude de sua propensão à inovação. Ele acrescenta que

\footnotetext{
uma vez dentro do sistema, as inovações se difundem por meio de uma rede de laços sociais. Essas conexões incluem laços fortes com formadores de opinião e laços fracos com os subgrupos sociais, que fazem a ponte entre as sub-redes que de outra forma permaneceriam desconectadas.
}

Para esse mesmo autor, a difusão de inovação é um sistema adaptativo complexo, pois depende de múltiplos agentes em interações sociais dinâmicas. Como é um processo social, a ação de um agente pode influenciar toda uma rede. A meta da inovação é sempre a emergência, ou seja, a transformação de uma ordem aparentemente estável em nova ordem mais organizada e adaptada. A difusão de inovação é, portanto, não linear, irreversível e não determinística. Ela se caracteriza pela mudança em uma rede de comunicações. Ele acrescenta que mudanças podem acontecer em cascata quando o sistema processa novas informações sobre uma inovação, supera uma incerteza e opera uma mudança de fase (não adoção para adoção). A rejeição no nível individual ou micro pode também levar ao fracasso da adoção da inovação. 
A inovação trazida pela Internet permitiu, no contexto educacional, não apenas consumir informação, mas também produzir e divulgar conteúdo na web. Isso mudou as relações sociais, pois se ampliaram as redes de interação, a diversidade de informações e de pontos de vista, fazendo com que o conhecimento ficasse acessível a todos que pudessem se conectar.

\section{LINGUAGEM E MUDANÇAS NA PANDEMIA}

Vejam o que está aconteceu conosco. Em função da pandemia, vários gêneros da linguagem circularam na sociedade (decretos, boletins, conversa, mensagens no WhatsApp e em diversas redes sociais, MSN, sites diversos, memes, vídeos, entrevistas na TV e no rádio, marcas nos chão direcionando os intervalos das filas, fitas de isolamento impedindo acesso a praças, etc.). Experiências foram relatadas na comunicação pessoal e na comunicação de massa.

No entanto, essas narrativas sobre a pandemia não conseguiram convencer certas pessoas de que precisavam mudar seu comportamento e criar distanciamento social. A inovação no comportamento passou, em alguns lugares, a ser imposta com a criação de decretos, e com multas. A imprensa relatou até a repressão de milícias no Rio de Janeiro para obrigar as pessoas a ficarem em casa. Na minha cidade, Belo Horizonte, houve um decreto municipal que nos obrigou a usar máscaras e, em outras, houve lockdown, como em São Luiz, mas nem todos aceitaram mudar seus comportamentos.

A escrita no computador também revolucionou as relações humanas e sofreu e sofre repressão. Em 2011, as redes sociais como o Facebook o Twitter contribuíram para a queda de regimes políticos na Tunísia e no Egito. O governo da Líbia, no mesmo ano, bloqueou a Internet para impedir a organização dos manifestantes através de redes sociais. O acesso ao Linkedinfoi bloqueado na China, pois seus usuários estariam usando essa rede para organizar protestos. A comunidade de professores não nativos de inglês da associação TESOL criou um blog no Blogspot e sua direção foi comunicada, em mensagem enviada à lista de discussão do grupo, que no Kazaquistão, os leitores não teriam como acessar o blog do grupo, pois, por determinação governamental, o Blogspot estava bloqueado naquele país.

Estes são exemplos já velhos, mas temos exemplos mais atuais. Vimos a China censurando informações na Internet sobre o covid-19. No Brasil, as informações do Ministérios da Saúde passam pela Secretaria de Comunicação do Governo Federal (Secom) e a divulgação diária de números de mortos foi censurada em junho de 2020, obrigando os órgãos de imprensa a criarem um consórcio para apurar e divulgar dados sobre a pandemia. 
E a censura aos professores? Nunca foram tão vigiados e ameaçados por seus patrões, pelos pais, pelos próprios alunos e pelos grupos de ódio dessa nova era da escola COM partido. Sim com partido, pois querem impor aos professores ideias retrógadas e formas de ensinar que contrariam a formação, a crenças e as práticas de muitos desses professores.

A inovação tecnológica tornou o professor um participante permanente do BBE - Big Brother Escola. Alunos filmam os professores e os expõem nas redes sociais. Vereadores fascistas invadem escolas para vigiar o professor. Em Belo Horizonte, um desses fiscais da moralidade filmou uma professora e estudantes menores de idade que estavam voltando de um festival de curtas no Palácio das Artes e fez uma falsa denúncia sobre a visita de estudantes, menores de idade, a uma exposição que ele considerava imprópria. Certamente quem está lendo este texto tem muitos outros exemplos de censura à informação e à arte.

A pandemia impulsionou mudança visível no uso de tecnologia digital. A emergência das lives durante a pandemia é um bom exemplo. Provavelmente, alguém vai dizer que não é live, mas transmissão ao vivo pela Internet. Esse apego à terminologia, aos rótulos, me lembra de Umberto Eco no livro Vertigem das listas. Os humanos gostam de rotular, classificar, criar ordem. Mas a linguagem não se deixa classificar.

A live onde apresentei este texto aconteceu porque aceitei, com prazer, um convite, mas muitas estão acontecendo por imposição. O que Rogers não previu na sua teorias sobre a inovação é que ela poderia acontecer pela força, como vemos em Maquiavel que dizia "a natureza dos povos é vária, sendo fácil persuadi-los de uma coisa, mas difícil firmálos nessa persuasão" (MAQUIAVEL, 1973, p. 31).

Eu, por exemplo, fui persuadida a comprar uma máquina de fazer pão, mas nem a pandemia firmou essa persuasão. Ela continua inativa. E Maquiavel continua, "Convém, assim, estar preparado para que, quando não acreditarem mais, se possa fazê-los crer pela força" (MAQUIAVEL, 1973, p. 31). Com a pandemia milhares de alunos e professores foram obrigados pela força/pelo poder a migrar para o mundo da internet. Ficaram de fora os que não têm acesso. Isso não quer dizer que muitos dos que estão contrariados não usem seu celulares, por exemplo, para interagir com familiares e amigos, para ver vídeos no YouTube.

O que está acontecendo com os alunos e professores? Ensino remoto emergencial, ensino a distância, ensino on-line, aprendizagem tutorada, homeschooling, ensino mediado por computador. Não sei. Não estou preocupada com as listas e a perturbação que elas nos causam por não serem finitas, por não permitirem incluir todos os exemplares. A pandemia comprova que sempre podemos incluir novos exemplares de comportamento. Não importa o nome. 
Trabalho com tecnologia digital desde 1997 e repeti a seguinte frase em algumas palestras e comunicações: "As máquinas dominam as comunicações no mundo moderno (...). O ambiente linguístico tem sido recriado artificialmente e o professor e o livro têm sido forçados a se integrarem a esses novos meios de transmissão" (KELLY, 1969, p.238).

Essas afirmações parecem ter sido feitas hoje, mas foram feitas por Kelly ao final da década de 60, mais precisamente em 1969. A atualidade dessa reflexão nos leva a afirmar que o homem está irremediavelmente preso às ferramentas tecnológicas em uma relação dialética entre a adesão e a crítica ao novo. O sistema educacional sempre se viu pressionado pela tecnologia, do livro ao computador, e faz parte de sua história um movimento recorrente de rejeição, inserção e normalização.

Quando surge uma nova tecnologia, a primeira atitude é a de desconfiança e de rejeição. Aos poucos, a tecnologia começa a fazer parte das atividades sociais da linguagem e a escola acaba por incorporá-la em suas práticas pedagógicas. Após a inserção, vem o estágio da normalização, definido por Chambers e Bax (2006, p. 465) como um estado em que a tecnologia se integra de tal forma às práticas pedagógicas que deixa de ser vista como cura milagrosa ou como algo a ser temido.

Faço uma digressão agora para falar brevemente sobre a história da Internet no Brasil.

\section{A HISTÓRIA DA INTERNET NA EDUCAÇÃO BRASILEIRA}

O acesso à rede mundial de computadores no Brasil aconteceu em 1991 com a criação da Rede Nacional de Pesquisa (RNP) pelo CNPq. A rede interligou várias universidades e os professores universitários começaram a "falar" com seus pares no exterior, ainda de forma precária, pois o sistema da época funcionava de forma muito semelhante às máquinas de escrever. O acesso público só teve início em 1994, com as provedoras particulares, e, em 1997, chegou a web nos moldes que conhecemos hoje. Surgiram novas formas de comunicação e os aprendizes de línguas estrangeiras puderam, pela primeira vez, interagir com falantes das línguas que aprendiam por meio de e-mail, listas de discussão e fóruns. Pela primeira vez, temos uma tecnologia que permite experiências linguísticas não artificiais e a língua pode ser entendida como comunicação. No entanto, 23 anos depois, essa tecnologia ainda não é de acessível a todos.

Tanto os livros como o computador convivem até hoje com a tensão entre a adoção e a rejeição na criação de uma nova ordem gerada pela difusão da inovação. A introdução desses artefatos na sociedade, em épocas tão distantes uma da outra, geraram mudanças na circulação da informação. Mudança é uma palavra chave para se entender o que é um sistema complexo e é de se esperar que o impacto das inovações tecnológicas gere tensões entre a ordem constituída e a promessa de uma nova ordem. 
Esses dois suportes, livro e computador, fizeram emergir novos gêneros e novas formas de circulação da informação e também de acesso ao conhecimento. Livros inspiraram revoluções políticas e causaram mudanças comportamentais. $\mathrm{Na}$ internet, os blogs pessoais abrigaram repórteres não oficiais de nossa história e sites, como foi o caso do Wikileaks (<http://wikileaks.org/>) que trouxe a público práticas de linguagem de círculos restritos da diplomacia internacional, revelando inconfidências que abalaram estruturas políticas. No Brasil, o Intercept Brasil desvelou os bastidores da imparcialidade e da ilegalidade da república de Curitiba na operação lava-jato.

As mudanças não são lineares, ou seja, elas não são proporcionais à criação das tecnologias inovadoras. Transformações acontecem através da amplificação de pequenas diferenças no comportamento de um sistema, quando novidade, criatividade e inovação podem emergir. No entanto, no caso do contexto educacional, não basta haver um novo artefato disponível para alunos e professores, pois muitos outros elementos interagem no sistema complexo da educação interferindo na difusão da inovação.

A apropriação das inovações gera tensões, resistências e censura e as mudanças não estão diretamente associadas aos artefatos, mas sim a comportamentos cristalizados na comunidade, a atratores.

Voltando a história, como reagiu o governo federal em relação às tecnologias? Em 1997, foi criado o Programa Nacional de Tecnologia Educacional (Prolnfo) para promover o uso pedagógico de Tecnologias de Informática e Comunicações na rede pública de ensino fundamental e médio. O Prolnfo equipou as escolas do ensino básico com um kitcomposto por um aparelho de televisão, um videocassete, uma antena parabólica e uma caixa de fitas VHS para gravar programas da TV Escola. O programa foi um fracasso. Muitos aparelhos não saíram das caixas e outros não sabiam usar os equipamentos.

Em 2010, foi a vez do PROUCA - Um Computador por Aluno, que eram laptops, os UCAs, que para cada aluno, mas que só poderiam ser carregados nas escolas. Teixeira (2012) acompanhou as ações iniciais do projeto na cidade de Tiradentes em Minas Gerais. Ela pretendia investigar o uso dos UCAs por professores de língua inglesa no ensino médio, mas constatou que o projeto não foi implantado nem nas séries finais do ensino fundamental e nem no ensino médio porque a escola estadual não havia conseguido construir a rede de conexão com a Internet. Esse fato a obrigou a direcionar a pesquisa dela para o ensino de língua portuguesa nas séries iniciais do ensino fundamental. O recebimento dos laptops foi imposto aos docentes, bem como o número mínimo de vezes que deveriam utilizá-los em sala de aula.

O que percebemos, a partir dos dados de Teixeira (2012), é que, para algumas professoras, a inovação foi significativa e alterou a maneira de elas se relacionarem com o conteúdo e com a turma, mas para outras, não teve significado. 
Os dados de Teixeira (2012) revelam que não basta levar a tecnologia até as escolas. Para que a difusão se dê de forma eficiente, é preciso encontrar adeptos dispostos a expandir a rede de usuários. Muitas vezes, a resistência está nas direções dessas escolas que não são suficientemente proativas nem para providenciar a compra de cabos para se construir a rede. Mesmo as escolas conectadas, em muitos lugares, ainda passam por limitações na conexão com a Internet, pois o serviço de Internet no Brasil ainda precisa melhorar.

A inovação tecnológica da Internet foi equivocadamente interpretada como acesso a equipamento sem cuidar da infraestrutura e do acesso a todos. Apesar do "incentivo" com a criação de alguns laboratórios de informática, a falta de acesso e a má vontade de alguns gestores impediram seu uso. Alunos foram proibidos de levar celulares para as salas de aula e professores precisavam ter permissão especial para fazer atividades usando celulares. Houve até decretos em alguns lugares.

Mas houve também adeptos que, livres do controle perverso dos gestores, usaram e abusaram (no bom sentido) de todas as affordances, os propiciamentos que a Internet trazia. Usaram recursos gratuitos, pagos e surgiram projetos colaborativos com alunos de outras escolas e de países diferentes. Cursos foram dados em plataformas educacionais, por e-mail, chat, Orkut, Facebook e WhatsApp. Ironicamente o vídeo que até então tinha sido pouco apropriado pelos professores, passou a fazer sucesso com aulas e apresentações de alunos no YouTube e os celulares contribuem para isso.

Ainda não havíamos atingido a fase da normalização, quando a pandemia nos atropelou. A prova disso são as inúmeras dissertações e teses demonstrando o benefício do uso dessa e daquela ferramenta digital. Esses trabalhos reforçam o que dizem Rogers et a/ (2005):

quando os indivíduos adotam uma inovação, seu comportamento no nível micro contribui para o comportamento no nível macro. À medida que a taxa de adoção da inovação acelera e a difusão da inovação aumenta, um comportamento adaptativo emerge no nível do sistema.

Esse fenômeno pode ser entendido como bifurcação do sistema, ou mudança de fase. A bifurcação ocorre porque o sistema torna-se instável com a introdução da inovação e todos os subprodutos que vêm juntos.

\section{PALAVRAS FINAIS}

$\mathrm{Na}$ verdade, o Brasil não se preparou para o presente. Fechou os olhos para a importância das tecnologias digitais. Aliás, sempre teve os olhos fechados para a saúde e para a educação. 
Em texto recente - A cruel pedagogia do vírus - Boaventura de Souza Santos faz a seguinte análise:

\begin{abstract}
As pandemias mostram de maneira cruel como o capitalismo neoliberal incapacitou o Estado para responder às emergências. As respostas que os Estados estão a dar à crise variam de Estado para Estado, mas nenhum pode disfarçar a sua incapacidade, a sua falta de previsibilidade em relação a emergências que têm vindo a ser anunciadas como de ocorrência próxima e muito provável (SANTOS, 2020).
\end{abstract}

A tecnologia digital nos ajudou a romper, metaforicamente, com as paredes das nossas salas de aula, nos levando para o mundo virtual. O que não se esperava era que a sala de aula fosse arrombada como está sendo agora e que o professor fosse tão pressionado e policiado. A todo o momento, me chegam depoimentos de professores dizendo que são obrigados a gravar vídeos antes de seus horários de aula regular. Isso implica roteiro, gravação, edição. Quem já fez isso sabe o tempo que se gasta, mas esse tempo não tem sido contado como trabalho. Quando a aula é ao vivo, alguns pais se intrometem e dão palpites e alguns alunos e pais gravam os professores e ameaçam suas faces.

A tecnologia digital nos ajudou também a derrubar, metaforicamente, as paredes das nossas casas. Novas práticas sociais de linguagens emergiram, como os botecos e jantares virtuais e outras se intensificaram, como as "lives", ou palestras virtuais e os minicursos em vídeo, como os oferecidos pela Edições Parábola em seu canal no YoutTube. É surpreendente ver o número de pessoas que assistem aos vídeos.

Recorrendo aos sistemas complexos, podemos dizer que quando um novo elemento entra no sistema, ele pode causar turbulência e desorganizar o sistema, mas da desordem ou do caos (sempre um momento ótimo para aprendizagem), emerge uma nova ordem e o sistema se auto-organiza. A auto-organização é uma característica importante dos sistemas complexos adaptativos.

Mas a pergunta que não quer calar é: Como serão nossas práticas de linguagem, especialmente na sala de aula, após a pandemia?

Eu gostaria de responder com os versos de Lulu Santos que, poeticamente parafraseia a ideia de Heráclito de que "tudo está em um estado de fluxo".

\footnotetext{
Nada do que foi será

De novo do jeito que já foi um dia

Tudo passa, tudo sempre passará

(...)

Tudo muda o tempo todo no mundo
}

E, no mundo da pandemia, tudo muda rápido demais.

Encerro este texto com o meu pesar por todos que foram vítimas da pandemia e da ignorância de alguns governantes. Lamento pelas perdas de todos nós. Desejo que quando este texto for lido, a pandemia tenha passado. 


\section{REFERÊNCIAS}

CHAMBERS, A.; BAX, S. Making CALL work: Towards normalisation. System. v. 34, p. 465-479, 2006.

CHARTIER, R. A ordem dos livros: leitores, autores e bibliotecas na Europa entre os séculos XIV e XVIII. Trad. Mary Del Priore. Brasília: Editora Universidade de Brasília, 1994.

ECO, Umberto. A vertigem das listas. Trad. Eliana Aguiar. Rio de Janeiro: Record, 2010.

FONSECA, Jose. Complexity and Innovation in Organisations. London: Routledge, 2002.

GLEICK, J. The Information: a history, a theory, a flood. New York: Pantheon Books, 2011. Edição Kindle.

KELLY, Louis G. 25 centuries of language teaching; an inquiry into the science, art, and development of language teaching methodology, 500 B.C.-1969. Rowley, Massachusetts: Newbury House, 1969.

MAQUIAVEL, N. O Príncipe. Trad. Lívio Xavier. São Paulo: Abril Cultural, 1973. (Os Pensadores).

PAIVA, Vera Lúcia Menezes de Oliveira. A tecnologia na docência em línguas estrangeiras: convergências e tensões. In: DALBEN, Angela.; DINIZ, Júlio.; LEAL, Leiva, SANTOS, Lucíola (Orgs). Convergências e tensões no campo da formação e do trabalho docente. Belo Horizonte: Autêntica, 2010, p. 595-613.

PAIVA, Vera Lúcia Menezes de Oliveira. Inovações tecnológicas: o livro e o computador In: VETROMILLE-CASTRO, Rafael; HEEMANN, Christiane; FIALHO, Vanessa Ribas. Aprendizagem de linguas: CALL, atividade e complexidade. Uma homenagem aos 70 anos do Prof. Dr. Vilson José Leffa. Pelotas: Educat, 2012.

SANTOS, Boaventura de Souza. A cruel pedagogia do virus. Coimbra: Almedina,

ROGERS, Ever M. et al. Complex Adaptive Systems and the Diffusion of Innovations. The Innovation Journat: The Public Sector Innovation Journal, v. 10, n. 3, p. 1-26, 2005. Disponível em: https://www.innovation.cc/volumesissues/rogers-adaptivesystem7final.pdf. Acesso em 3 maio 2020.

TEIXEIRA, Adriana Gouvea Dutra. Difusão tecnológica no ensino de línguas: o uso de computadores portáteis nas aulas de língua portuguesa sob a ótica da complexidade. 2012. Tese (Doutorado em Estudos Linguísticos) Faculdade de Letras, Universidade Federal de Minas Gerais, 2012.

VIDAL, José Manuel. Sexualidad y condición homossexual em la morl Cristiana. Buenos Aires: San Pablo, 2012. 